\title{
Scanography Method for Assessment of Needle Free Injection Dispersion Pattern of Vaccine in Pig Soft Tissues
}

\section{Bianco $\mathrm{C}^{{ }^{*}}$ and Vila $\mathrm{T}^{2}$}

${ }^{1}$ Department of Veterinary Medical Science, Bologna, Italy

${ }^{2}$ Merial S.A.S., Lyon, France

*Corresponding author: Bianco carlo, Department of Veterinary Medical Science, Bologna, Italy, Tel: 39 051- 2097961; E-mail: carlo_blanc@yahoo.it

Received August 28, 2014; Accepted September 15, 2014; Published September 20, 2014

Citation: Bianco C, Vila T (2014) Scanography Method for Assessment of Needle Free Injection Dispersion Pattern of Vaccine in Pig Soft Tissues. J Vaccines Vaccin 5: i102. doi: 10.4172/2157-7560.1000i102

Copyright: ( 2014 Bianco C, et al. This is an open-access article distributed under the terms of the Creative Commons Attribution License, which permits unrestricted use, distribution, and reproduction in any medium, provided the original author and source are credited.

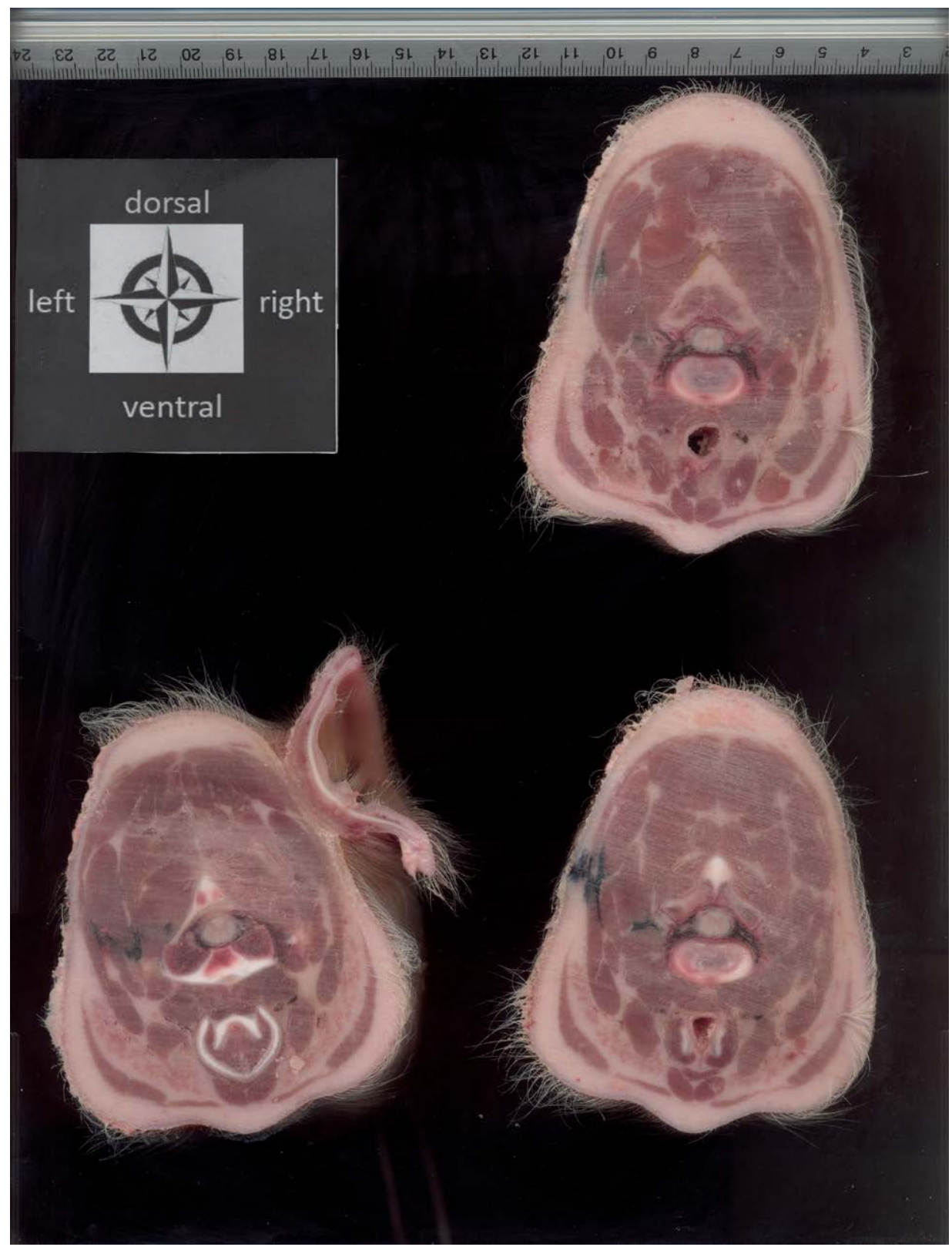

Figure 1: Frozen cross-sectional slices of neutered male piglet (body live weight=5.9 kg), vaccinated with Circovac spiked with black ink and NFID Valery. (Lower left: first rostral slice; lower right: second slice-injection site; upper right: third caudal slice). (Original image, flatbed scanner settings: 1200 dpi; $10200 X 14040$ pixel, Jpeg). 
Citation: Bianco C, Vila T (2014) Scanography Method for Assessment of Needle Free Injection Dispersion Pattern of Vaccine in Pig Soft Tissues. J Vaccines Vaccin 5: i102. doi: 10.4172/2157-7560.1000i102

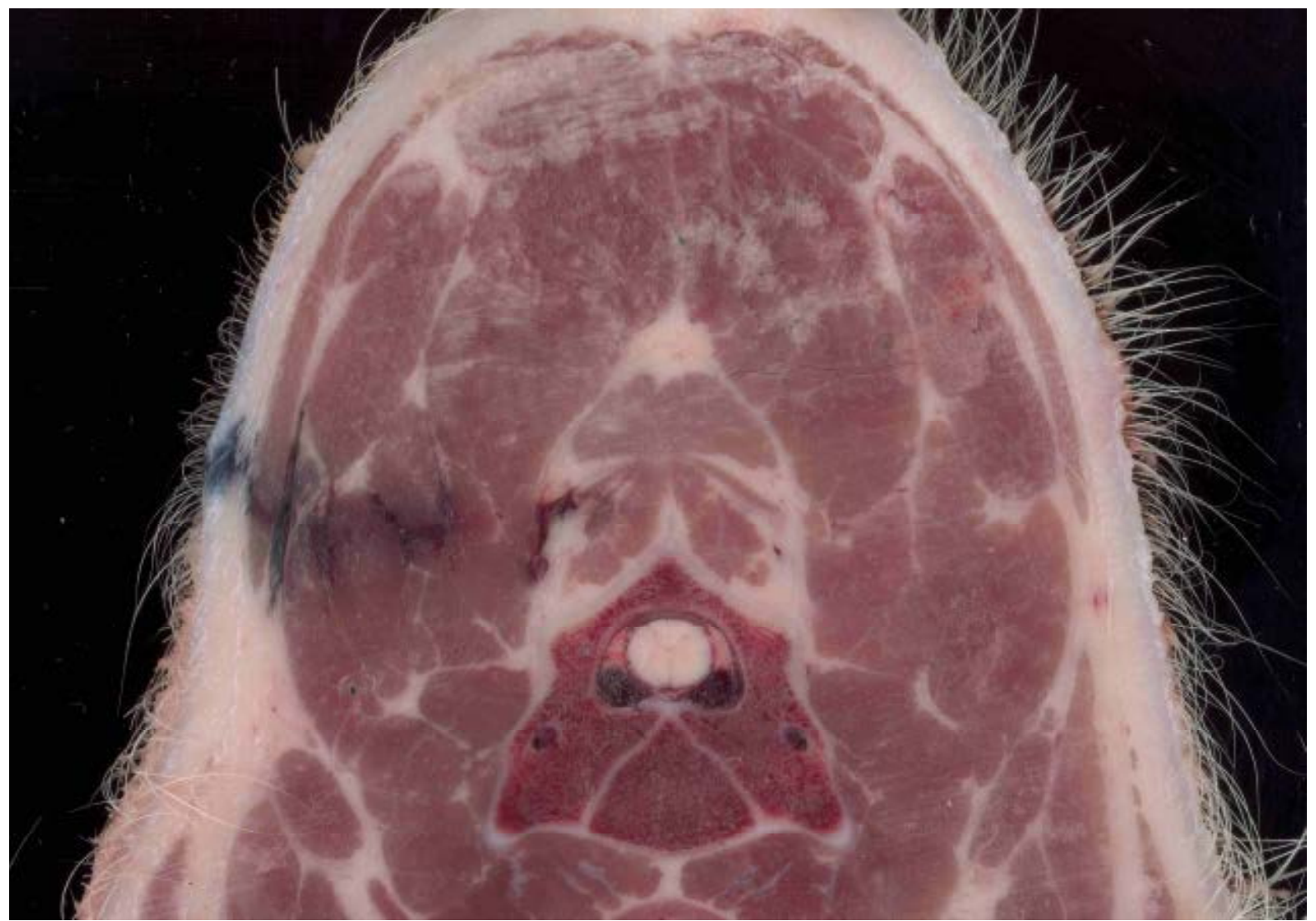

Figure 2: Close up of Frozen cross-sectional slice of female piglet (body live weight=18.0 kg), vaccinated with Circovac spiked with black ink and NFID Valery. (Second slice-injection site). (Original image, flatbed scanner settings: $1200 \mathrm{dpi} ; 10200 \times 14040$ pixel, Jpeg).

\section{Description}

The term needle free is used to describe an extensive range of drug delivery technologies, which consists of devices that do not use a needle to inject drugs through the skin [1]. Focusing on veterinary medicine, vaccination is a significant component of standard management practices in swine husbandry, and needle-free injection device (NFID) possesses several advantages [2].

This paper describes a simple and effective visual method to study the pattern of dispersion of a NFID injection in animal soft tissues; to the best knowledge of the authors, there are only few reported trials focusing on delivery efficacy assessment and dispersion pattern of needle-free injection devices in animals [3], while available controlled studies trials addresses the elicited immune response of NFID vaccinated animals..

Conventional piglets (body weight $=5-20 \mathrm{~kg}$ ) were vaccinated on the left side of the neck with NFID Valery injector (Giordano Poultry Plast SPA, Italy), with black colored ink spiked Circovac (Merial, Lyon, France), $1 \mathrm{cc}$ ink/100 cc vaccine. Piglets were injected with $0.5 \mathrm{ml}$ of the vaccine, according to the data sheet. Immediately after vaccination, piglets underwent euthanasia with the following pharmacological protocol: $0.4 \mathrm{ml} \mathrm{IM}$ of Tiletamine+Zolazepam IM (Zoletil ${ }^{\circledR}$ Virbac, FR, after 15 minutes, $3 \mathrm{ml}$ of Pentothal IV and $3 \mathrm{ml}$ of Tanax ${ }^{\bullet}$ IV (MSD Anim Heath Srl-Italy).

Freezing of piglet carcases in vertical recumbency was carried out $\left(48 \mathrm{~h} ;-20^{\circ} \mathrm{C}\right)$ and subsequently frozen,cross-sectional slices were obtained (thickness $=1 \mathrm{~cm}$ ). The vertical position allowed bilateral symmetry of the carcases. Images of serial cross sectional slices were acquired by means of an ordinary flatbed scanner protected by a glass plate (Figures 1 and 2).

The proposed method allowed a rapid gross visualization of dispersion pattern and eventual lesions (hemorrhages) and the possibility of digital handling and analysis of images. Moreover this method can represent a model for NFID local safety assessment and comparison between devices or drugs. Finally, this in vivo model can serve as a model for human NFID vaccine delivery.

\section{Statement of Animal Care}

The experimental trial was approved by the Animal Experimentation Ethical and Scientific Committee - Alma Mater Studiorum of the University of Bologna; afterwards was submitted to and approved by the Italian Ministry of Health. The study was conducted in accordance with European legislation regarding the protection of animals used for experimental and other scientific purposes (Council Directive 86/609/EEC). 
Citation: Bianco C, Vila T (2014) Scanography Method for Assessment of Needle Free Injection Dispersion Pattern of Vaccine in Pig Soft Tissues. J Vaccines Vaccin 5: i102. doi: 10.4172/2157-7560.1000i102

Page 3 of 3

\section{Acknowledgement}

Authors would like to express great appreciation to Professor Sarli G. and Professor Ostanello F. for valuable ideas and hints, to Mr Labate A. for precious technical support, and to Crosby H. (BVMS, MRCVS, resident in Veterinary Pathology-Liverpool University) for mother tongue proofreading and constructive suggestions.

\section{References}

1. Patwekar SL, Gattani SG, Pande MM (2013) Needle free injection system: a review. Int J Pharm Pharm Sci 5: 14-19.

2. Chase CCL, Daniels CS, Garcia R, Milward F, Nation T (2008) Needle-free injection technology in swine: Progress toward vaccine efficacy and pork quality. J Swine Health Prod 16: 254-261.

3. Phillips JC, Blackford JT, Lembcke LM, Grosenbaugh DA, Leard T (2011) Evaluation of Needle-free Injection Devices for Intramuscular Vaccination in Horses. J of Equine Vet Sci 31: 738-743 